\title{
UJI AKTIVITAS ANTIOKSIDAN EKSTRAK KAYU BAYUR SULAWESI (Pterospermum celebicum Miq.) DENGAN METODE PENANGKAPAN RADIKAL BEBAS DPPH (2,2-diphenyl-1-picryl-hydrazyl)
}

\author{
Sapri \\ Akademi Farmasi Samarinda \\ e-mail : sapri_juli86@yahoo.co.id
}

\begin{abstract}
An antioxidant activity test of Bayur Sulawesi (Pterospermum celebicum Miq.) wood ekstract by method of the scavenging free radical DPPH (2,2-diphenyl-1-picryl-hydrazyl) had been performed. The research was aimed to establish antioxidant activity of Bayur Silawesi (P. celebicum Miq.) wood extract in scavenging the free radical DPPH. The extraction was conducted by maceration method with methanol and subsequently was partitioned by $n$-hexan, chloroform and ethyl acetat, and tested for free radical DPPH scavenger activity. Results of antioxidant activity test indicated that $I C_{50}$ value of methanol, $n$-hexan, chloroform and ethyl acetat extracts were 263 ppm, 277.5 ppm, 240.95 ppm and 172.9 ppm.
\end{abstract}

Key words: Antioxidant activity, Bayur Sulawesi (Pterospermum celebicum Miq.), free radical $D P P H$

\begin{abstract}
ABSTRAK
Telah dilakukan penelitian uji aktivitas antioksidan ekstrak kayu Bayur Sulawesi (Pterospermum celebicum Miq.) dengan metode penangkapan radikal bebas DPPH (2,2diphenyl-1-picryl-hydrazyl). Penelitian ini bertujuan untuk mengetahui aktivitas antioksidan ekstrak kayu Bayur Sulawesi (P. celebicum Miq.) dalam penangkapan radikal bebas DPPH. Ekstraksi dilakukan dengan metode maserasi menggunakan pelarut metanol dan selanjutnya dipartisi dengan n-heksan, kloroform dan etil asetat dan diuji aktivitas penangkapan radikal bebas DPPH. Hasil uji aktivitas antioksidan menunjukkan bahwa nilai $\mathrm{IC}_{50}$ dari ekstrak metanol, n-heksan, kloroform dan etil asetat berturut-turut adalah 263 bpj, 277,5 bpj, 240,95 bpj dan 172,9 bpj.
\end{abstract}

Kata Kunci: Aktivitas antioksidan, Bayur Sulawesi (Pterospermum celebicum Miq.), radikal bebas DPPH

\section{PENDAHULUAN}

Tumbuhan di daerah tropis seperti Indonesia, hidup di bawah kondisi lingkungan yang keras baik faktor iklim maupun gangguan dari herbivora, serangga dan hama penyakit. Respon terhadap kondisi tersebut, tumbuhan mampu menghasilkan beraneka ragam senyawa kimia alami yang mempunyai bioaktivitas yang menarik. Senyawa-senyawa ini kemudian diketahui dapat bersifat sebagai insektisida, anti fungi, anti bakteri, anti radikal bebas (antioksidan) dan sitotoksik [1].

Tumbuhan adalah sumber antioksidan alami yang potensial. Efek antioksidan dari tumbuhan sebagian besar berhubungan dengan senyawa fenolik seperti flavonoid, 
Uji aktivitas antioksidan ekstrak kayu bayur sulawesi (Pterospermum celebicum miq.) Dengan metode penangkapan radikal bebas dpph (2,2-diphenyl-1-picryl-hydrazyl)

asam fenolik, tannin, dan fenolik diterpen [2-4]. Adanya gugus fenol yang mudah teroksidasi oleh radikal bebas akan membentuk suatu radikal bebas yang terstabilkan oleh delokalisasi elektron dan akan menangkap radikal bebas yang lain. Bioaktivitas anti radikal bebas senyawa fenolik berbanding lurus dengan banyaknya gugus hidroksi yang tersubtitusi, maka semakin banyak gugus hidroksi semakin tinggi aktivitas anti radikal bebas [1].

Salah satu tumbuhan yang diduga mengandung senyawa yang memiliki aktifitas antioksidan adalah Bayur Sulawesi atau dalam bahasa daerah disebut Banjoro (Pterospermum celebicum Miq.).

Tumbuhan (Pterospermum celebicum Miq.) merupakan tumbuhan khas dari Sulawesi. Telah dilakukan penelitian mengenai pemeriksaan farmakognostik tumbuhan Pterospermum celebicum Miq. dan penapisan komponen kimia secara kromatografi lapis tipis, dan dilaporkan bahwa pada daun, kulit batang, dan batang ditemukan adanya senyawa tannin, katekin, fenol dan steroid [5-8].

Berdasarkan uraian tersebut di atas, maka dilakukan penelitian untuk mengetahui pengaruh ekstrak kayu Bayur Sulawesi $(P$. celebiqum Miq.) dalam penangkapan radikal bebas DPPH (2,2-diphenyl-1picryl-hydrazyl), untuk itu dilakukan uji aktivitas antioksidan ekstrak kayu Bayur Sulawesi ( $P$. celebiqum Miq.) dengan metode penangkapan radikal bebas DPPH. Penelitian ini bertujuan untuk mengetahui aktivitas antioksidan ekstrak kayu Bayur Sulawesi ( $P$. celebicum Miq.) dalam penangkapan radikal bebas DPPH. Besarnya aktivitas penangkapan radikal bebas DPPH ditandai dengan besarnya $\mathrm{IC}_{50}$ (50\% Inhibitory concentration) yang didapatkan dari analisis regresi linier probit persen penangkapan radikal bebas DPPH dan log konsentrasi. Menurut Cos, dkk. dalam Masrifah (2006) apabila $\mathrm{IC}_{50}$ lebih kecil dari 1000 bpj maka ekstrak tersebut mempunyai aktivitas sebagai antioksidan [1], dan menurut Blois dalam Hanani (2005) menyatakan bahwa ekstrak dengan nilai $\mathrm{IC}_{50}$ kurang dari 200 bpj memiliki aktivitas antioksidan yang kuat [9].

\section{METODE}

\section{Alat dan Bahan}

Alat-alat yang digunakan dalam penelitian ini adalah corong pisah $250 \mathrm{ml}$ (Iwaki Pyrex $\left.{ }^{\circledR}\right)$, labu tentukur $5 \mathrm{ml}, 10 \mathrm{ml}, 100 \mathrm{ml}$ (Iwaki Pyrex ${ }^{\circledR}$ ), mesin penggiling, mikropipet $10-100 \quad \mu 1$ dan $1000 \quad \mu 1$ $\left(\right.$ Socore $\left.^{\circledR}\right)$, neraca analitik $\left(\right.$ Sartorius $\left.^{\circledR}\right)$, seperangkat alat rotavapor (Buchii), spektrofotometer UV-VIS (Agilent ${ }^{\circledR}$ ).

Bahan-bahan yang digunakan dalam penelitian ini adalah kayu Bayur Sulawesi ( $P$. celebicum Miq.), etanol absolute $\left(\right.$ Merck $\left.^{\circledR}\right)$, asam askorbat $\left(\right.$ Merck $\left.^{\circledR}\right), 2,2-$ diphenyl-1-picryl-hydrazyl

$\left(\right.$ Sigma $\left.^{\circledR}\right)$, etil asetat p.a $\left(\right.$ Merck $\left.^{\circledR}\right)$, kloroform p.a $\left(\operatorname{Merck}^{\circledR}\right)$, methanol p.a $\left(\right.$ Merck $\left.^{\circledR}\right), \quad$ n-heksan p.a $\left(\right.$ Merck $\left.^{\circledR}\right)$.

\section{Penyiapan Sampel}

\section{Pengambilan dan Pengolahan Sampel}

Sampel kayu Bayur Sulawesi (P. celebicum Miq.) diambil dari Kabupaten Bantaeng, Sulawesi Selatan. Sampel kayu tersebut dipisahkan terlebih dahulu antara kulit dan kayunya, selanjutnya kayu dikeringkan dengan cara diangin-anginkan, terlindung dari sinar matahari langsung selama 3 hari, kemudian diserut. Hasil serutan kayu dikeringkan kembali dengan cara yang sama selama 1 hari kemudian diserbukkan 
Uji aktivitas antioksidan ekstrak kayu bayur sulawesi (Pterospermum celebicum miq.) Dengan metode penangkapan radikal bebas dpph (2,2-diphenyl-1-picryl-hydrazyl)

dengan mesin penggiling, selanjutnya sampel siap diekstraksi.

\section{Ekstraksi Sampel}

Sampel ditimbang sebanyak 500 g, lalu diekstraksi dengan metode maserasi menggunakan pelarut metanol. Sebelum diekstraksi, sampel direndam terlebih dahulu dengan cairan penyari metanol secukupnya dan dibiarkan terendam selama 12 jam. Setelah itu sampel diekstraksi dengan metanol sebanyak 2,5 liter selama 3 hari, kemudian disaring dan filtrat yang diperoleh dikumpulkan. Residu dimaserasi kembali dengan pelarut dan volume yang sama selama 3 hari. Filtrat yang telah dikumpulkan, dikisatkan menggunakan alat rotavapor, hingga didapat ekstrak kental metanol.

\section{Partisi}

Ekstrak kental metanol ditambahkan dengan $50 \mathrm{ml}$ metanol dan ditambahkan air $10 \%$. Kemudian dipartisi dengan metode cair-cair menggunakan pelarut n-heksan (5 x $50 \mathrm{~mL}$ ) sehingga didapatkan ekstrak metanol-air dan ekstrak n-heksan. Ekstrak n-heksan dikumpulkan lalu diuapkan sehingga didapat ekstrak kental n-heksan. Ekstrak metanol-air dipartisi kembali dengan pelarut kloroform $(5 \times 50 \mathrm{~mL}$ ) sehingga didapatkan ekstrak metanol-air dan ekstrak kloroform. Ekstrak kloroform dikumpulkan lalu diuapkan sehingga didapat ekstrak kental kloroform. Ekstrak metanol-air dipartisi kembali dengan pelarut etil asetat $(5 \times 50 \mathrm{~mL})$ sehingga didapatkan ekstrak metanol-air dan ekstrak etil asetat. Ekstrak etil asetat dikumpulkan lalu diuapkan sehingga didapat ekstrak kental etil asetat. Ekstrak metanol, nheksan, kloroform dan etil asetat diuji aktivitas penangkapan radikal bebas DPPH.

\section{Uji Aktivitas Antioksidan dengan Metode Penangkapan Radikal Bebas DPPH}

\section{Pembuatan Larutan DPPH 0,4 mM}

Larutan DPPH 0,4 mM dibuat dengan cara ditimbang DPPH sebanyak 0,0157 g dilarutkan dengan etanol absolut hingga $100 \mathrm{ml}$ dalam labu tentukur.

\section{Pengujian Aktivitas Antioksidan \\ Pengukuran Panjang Gelombang Maksimum DPPH}

Pengukuran dilakukan dengan memipet 1 $\mathrm{ml}$ DPPH 0,4 $\mathrm{mM}$ dan dicukupkan volumenya sampai $5 \mathrm{ml}$ dengan etanol absolut dalam labu tentukur $5 \mathrm{ml}$. Larutan ini dipindahkan ke dalam wadah gelas coklat dan dibiarkan selama 30 menit, selanjutnya diukur serapannya pada panjang gelombang maksimum.

\section{Pengukuran Aktivitas Antioksidan Ekstrak}

Untuk tiap ekstrak ditimbang sebanyak 100 mg kemudian dilarutkan dengan etanol absolut sebanyak $10 \mathrm{ml}$ sehingga diperoleh konsentrasi 10.000 bpj sebagai larutan stok. Dari larutan stok dipipet $250 \mu 1,200$ $\mu 1, \quad 150 \quad \mu 1$ dan $100 \mu l$ kemudian dicukupkan $10 \mathrm{ml}$ sehingga diperoleh konsentrasi $250 \mathrm{bpj}, 200 \mathrm{bpj}, 150 \mathrm{bpj}$ dan $100 \mathrm{bpj}$.

Pengujian dilakukan dengan memipet 100 $\mu 1$ larutan uji dari berbagai konsentrasi, lalu masing-masing ditambah $1 \mathrm{ml}$ DPPH 0,4 $\mathrm{mM}$ dan dicukupkan volumenya sampai 5 $\mathrm{ml}$ dengan etanol absolut. Campuran tersebut dikocok dan dibiarkan selama 30 menit pada suhu kamar dan pada ruangan yang terlindung dari cahaya. Selanjutnya diukur absorbansinya pada panjang gelombang maksimum. Hasil penetapan 
Uji aktivitas antioksidan ekstrak kayu bayur sulawesi (Pterospermum celebicum miq.) Dengan metode penangkapan radikal bebas dpph (2,2-diphenyl-1-picryl-hydrazyl)

aktivitas antioksidan dibandingkan dengan vitamin $\mathrm{C}$ yang sudah diketahui aktivitas antioksidannya.

\section{Pengukuran Aktivitas Antioksidan Larutan Pembanding Vitamin C}

Pembanding vitamin $\mathrm{C}$ murni ditimbang sebanyak $50 \mathrm{mg}$ kemudian dilarutkan dengan etanol absolut $10 \mathrm{ml}$ sehingga diperoleh konsentrasi 5000 bpj sebagai larutan stok.

Larutan stok dipipet $40 \mu 1,30 \mu 1,20 \mu 1$ dan $10 \mu 1$ dicukupkan volumenya sampai $5 \mathrm{ml}$ sehingga diperoleh konsentrasi $40 \mathrm{bpj}, 30$ bpj, 20 bpj dan 10 bpj.

Pengujian dilakukan dengan memipet 100 $\mu l$ larutan vitamin $\mathrm{C}$ dari berbagai konsentrasi, lalu masing-masing ditambah $1 \mathrm{ml}$ DPPH 0,4 $\mathrm{mM}$ dan dicukupkan volumenya sampai $5 \mathrm{ml}$ dengan etanol absolut. Campuran tersebut dikocok dan dibiarkan selama 30 menit pada suhu kamar dan pada ruangan yang terlindung dari cahaya.

Selanjutnya diukur absorbansinya pada panjang gelombang maksimum. Besarnya persentase penangkapan radikal bebas dihitung dengan rumus:

$\%$ Penangkapan radikal bebas $=\frac{\text { absorbsi DPPH }- \text { absorbsi sampel }}{\text { absorbsi DPPH }} \times 100 \%$

Nilai $\mathrm{IC}_{50}(50 \%$ Inhibitory concentration) ditentukan dengan analisis probit dari data log konsentrasi dengan probit persentase penangkapan radikal bebas.

\section{HASIL DAN PEMBAHASAN}

\section{Hasil Penelitian}

Hasil maserasi kayu Bayur Sulawesi (Pterospermum celebicum Miq.) sebanyak
$500 \mathrm{~g}$ dengan pelarut metanol sebanyak 2 $\mathrm{X}$ 2,5 liter masing-masing selama 3 hari diperoleh $20 \mathrm{~g}$ ekstrak kental metanol. Sebanyak $10 \mathrm{~g}$ ekstrak kental metanol dipartisi dengan pelarut dengan tingkat kepolaran yang berbeda, yaitu dengan $n$ heksan, kloroform dan etil asetat, sehingga didapat fraksi n-heksan sebanyak $2 \mathrm{~g}$, fraksi kloroform sebanyak $2 \mathrm{~g}$ dan fraksi etil asetat sebanyak $2,5 \mathrm{~g}$.

Hasil pengujian aktivitas antioksidan ekstrak kayu Bayur Sulawesi (P. celebicum Miq.) dengan metode penangkapan radikal bebas DPPH (2,2-diphenyl-1-pycrylhydrazyl) dapat dilihat pada tabel 1 dan 2.

\section{Pembahasan}

Sampel kayu Bayur Sulawesi (P. celebicum Miq.) yang telah dikeringkan dan diserbukkan, diekstraksi dengan metode maserasi yang merupakan metode penyarian secara dingin dan paling sederhana di antara metode lain, yaitu dengan cara merendam sampel dalam cairan penyari yang sesuai. Sampel dimaserasi dengan cairan penyari metanol untuk mengekstraksi komponen kimia baik yang polar maupun non polar. Pelarut metanol dipilih sebagai cairan penyari karena senyawa yang akan diekstraksi adalah senyawa fenolik. Ekstraksi senyawa fenolik dari jaringan tumbuhan dalam bentuk glikosida menggunakan pelarut metanol pada suhu kamar dengan cara maserasi $[18,19]$.

Kayu Bayur Sulawesi (P. Celebicum Miq.) yang telah kering diserbukkan terlebih dahulu untuk memperluas permukaan sampel sehingga kontak dengan cairan penyari lebih luas, dan proses penyarian dapat berlangsung dengan baik. Sebelum diekstraksi, sampel direndam terlebih dahulu dengan cairan penyari metanol secukupnya dan dibiarkan terendam selama 
Uji aktivitas antioksidan ekstrak kayu bayur sulawesi (Pterospermum celebicum miq.) Dengan metode penangkapan radikal bebas dpph (2,2-diphenyl-1-picryl-hydrazyl)

12 jam. Hal ini dilakukan karena pada saat dikeringkan, lapisan air dalam sel daun menguap sehingga terjadi pengerutan dan pori-pori kemudian berisi udara. Agar penyarian dapat berjalan dengan baik, maka udara dalam pori-pori harus dihilangkan dan diganti dengan cairan penyari.

Proses ini disebut pembasahan dan dimaksudkan untuk memberikan kesempatan yang sebesar-besarnya kepada cairan penyari memasuki seluruh pori-pori dalam sampel sehingga mempermudah ekstraksi selanjutnya.
Ekstrak kental metanol yang diperoleh selanjutnya dipartisi dengan metode ekstraksi cair-cair dalam corong pisah guna mendapatkan ekstrak berdasarkan tingkat kepolaran yang berbeda, karena prinsip dari ekstraksi cair-cair adalah pemisahan senyawa berdasarkan tingkat kepolarannya menggunakan 2 pelarut yang tidak saling bercampur. Prinsip ini dikenal sebagai sifat "like dissolve like", artinya pelarut akan melarutkan senyawa yang tingkat kepolarannya sama dengan pelarut tersebut.

Tabel 1. Nilai $I_{50}$ Terhadap Radikal Bebas DPPH Ekstrak Kayu Bayur Sulawesi (P. celebicum Miq.)

\begin{tabular}{c|c}
\hline Ekstrak & Nilai IC $_{50}$ bpj \\
\hline Metanol & 263 \\
n-Heksan & 277,5 \\
Kloroform & 240,95 \\
Etil Asetat & 172,9 \\
\hline
\end{tabular}

Tabel 2. Nilai IC50 Kontrol Positif Vitamin C

\begin{tabular}{c|c}
\hline Kontrol Positif & ${\text { Nilai } \text { IC }_{50} \text { bpj }}^{2}$ \\
\hline Vitamin C & 19,6 \\
\hline
\end{tabular}

Ekstrak kental metanol terlebih dahulu ditambahkan sedikit metanol kemudian ditambahkan air (7:3) dan dipartisi dengan pelarut dengan tingkat kepolaran yang berbeda yaitu, n-heksan, kloroform dan etil asetat. Dengan demikian senyawa aglikon dan glikon fenolik dapat dipisahkan. Aglikon fenolik akan terekstrak dalam pelarut semi polar dan glikonnya berada pada fase air sedangkan senyawa non polarnya akan terekstrak dalam pelarut nheksan [18].

Ekstrak metanol, n-heksan, kloroform dan etil asetat diuji aktivitas antioksidannya dengan metode penangkapan radikal bebas DPPH dengan menggunakan beberapa konsentrasi, yaitu masing-masing; $100 \mathrm{bpj}$, 150 bpj, 200 bpj dan 250 bpj. Sebagai kontrol positif, dan untuk pembanding digunakan vitamin $\mathrm{C}$ (konsentrasi 10, 20, 30 dan 40 bpj). Vitamin $\mathrm{C}$ digunakan sebagai kontrol positif karena vitamin $\mathrm{C}$ berfungsi sebagai antioksidan sekunder, yang cara kerjanya menangkap radikal bebas dan mencegah terjadinya reaksi berantai.

Besarnya aktivitas penangkapan radikal bebas $\mathrm{DPPH}$ ditandai dengan nilai $\mathrm{IC}_{50}$ (50\% Inhibitory concentration) yang didapatkan dari analisis probit persen penangkapan radikal bebas DPPH dan log konsentrasi.

DPPH menghasilkan radikal bebas aktif bila dilarutkan dalam etanol. Radikal bebas tersebut stabil dengan absorpsi maksimum pada panjang gelombang $517 \mathrm{~nm}$ dan dapat direduksi oleh senyawa antioksidan. 
Uji aktivitas antioksidan ekstrak kayu bayur sulawesi (Pterospermum celebicum miq.) Dengan metode penangkapan radikal bebas dpph (2,2-diphenyl-1-picryl-hydrazyl)

Metode penangkapan radikal bebas DPPH dipilih karena sederhana, mudah, cepat, peka dan hanya memerlukan sedikit sampel. Pada pelaksanaan uji antioksidan ekstrak kayu batang Bayur Sulawesi $(P$. celebicum Miq.) diawali dengan pembuatan spektra sinar tampak (360-720 nm) untuk mengamati apakah larutan DPPH mempunyai puncak $517 \mathrm{~nm}$. Hasil pengukuran menunjukkan bahwa larutan DPPH memiliki panjang gelombang maksimum $517 \mathrm{~nm}$ dengan absorbansi 0,595 .

Uji aktvitas antioksidan penangkapan radikal bebas DPPH menunjukkan bahwa ekstrak metanol, n-heksan, kloroform, etil asetat dan vitamin $\mathrm{C}$ mempunyai $\mathrm{IC}_{50}$ berturut-turut adalah $263 \mathrm{bpj}, 277,5 \mathrm{bpj}$, 240,95 bpj, 172,9 bpj dan 19,6 bpj.

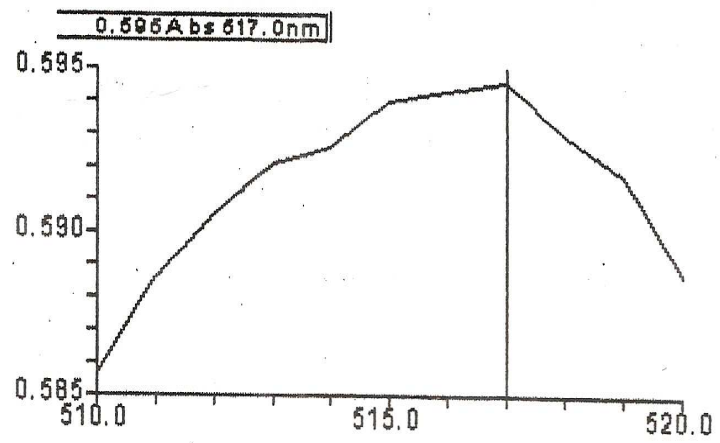

Gambar 1. Spektrum Sinar Tampak Larutan DPPH 0,4 mM pada Panjang Gelombang 517 nm.

Hasil uji aktivitas antioksidan menunjukkan bahwa keempat ekstrak kayu batang Bayus Sulawesi (Pterospermum celebicum Miq.) memiliki aktivitas sebagai antioksidan, karena memiliki $\mathrm{IC}_{50}$ kurang dari 1000 bpj [1] (ekstrak metanol, nheksan dan kloroform) dan kurang dari 200 bpj [9] untuk ekstrak etil asetat. Aktivitas antioksidan dari ekstrak kayu batang Bayur Sulawesi (Pterospermum celebicum Miq.)

J. Trop. Pharm. Chem. 2011. Vol 1. No. 3. berkaitan dengan kandungan senyawa yang terdapat pada masing-masing ekstrak.

Metanol merupakan pelarut yang bersifat polar yang dapat mengekstraksi senyawa polar dan non polar, sehingga kemungkinan semua senyawa yang terkandung di dalam kayu batang Bayur Sulawesi (Pterospermum celebicum Miq.) seperti tannin, katekin, fenol dan steroid dapat terekstraksi.

Ekstrak n-heksan diduga mengandung senyawa steroid, lemak atau minyak, senyawa-senyawa ini bersifat non polar sehingga dapat terekstraksi ke pelarut nheksan, beberapa senyawa steroid dan lemak atau minyak memiliki aktivitas antioksidan [22,23].

Ekstrak kloroform diduga mengandung senyawa flavon atau flavonol, senyawa ini cenderung mudah larut dalam pelarut kloroform [18], senyawa flavon atau flavonol memiliki aktivitas antioksidan [24]. Ekstrak etil asetat diduga mengandung senyawa penolik, senyawa ini cenderung mudah larut dalam pelarut etil asetat [1].

Hasil uji aktivitas antioksidan menunjukkan bahwa ekstrak etil asetat memiliki nilai $\mathrm{IC}_{50} \quad 172,9$ bpj. Hal ini menunjukkan bahwa ekstrak etil asetat kayu batang Bayur Sulawesi (P. celebicum Miq.) pada konsentrasi 172,9 bpj telah mampu menghambat radikal bebas DPPH sebanyak 50\%. Berdasarkan hasil tersebut dapat dikatakan bahwa ekstrak etil asetat mempunyai aktivitas antioksidan yang kuat dalam menghambat radikal bebas DPPH, karena pada konsentrasi kurang dari 200 bpj telah dapat menghambat $50 \%$ radikal bebas DPPH. Apabila dibandingkan dengan aktivitas antioksidan vitamin $\mathrm{C}$, aktivitas antioksidan ekstrak kayu batang Bayur Sulawesi (P.celebicum Miq.) masih 
Uji aktivitas antioksidan ekstrak kayu bayur sulawesi (Pterospermum celebicum miq.) Dengan metode penangkapan radikal bebas dpph (2,2-diphenyl-1-picryl-hydrazyl)

lebih rendah. Hal ini dikarenakan pada penelitian ini yang diuji masih berupa ekstrak kasar, sehingga masih ada kemungkinan senyawa murni yang dikandung memiliki aktivitas antioksidan yang lebih kuat dibandingkan ekstraknya.

Kemampuan menghambat radikal bebas DPPH tersebut berkaitan pula dengan senyawa fitokimia dan gugus hidroksi yang terdapat pada senyawa tersebut. Bayur Sulawesi ( $P$. celebicum Miq.) mengandung senyawa fenolik. Senyawa fenolik yang banyak terdapat pada kayu batang adalah tannin yang merupakan bentuk senyawa polifenol yang banyak terdapat gugus hidrosil. Sehingga ekstrak etil asetat memiliki aktivitas antioksidan yang lebih kuat dibandingkan dengan ekstrak yang lainnya.

\section{KESIMPULAN DAN SARAN \\ Kesimpulan}

Dari penelitian yang telah dilakukan dapat disimpulkan bahwa ekstrak kayu Bayur Sulawesi (Pterospermum celebicum Miq.) memiliki aktivitas antioksidan. Hasil uji aktivitas antioksidan menunjukkan bahwa nilai $\mathrm{IC}_{50}$ dari ekstrak metanol, n-heksan, kloroform dan etil asetat berturut-turut adalah 263 bpj, 277,5 bpj, 240,95 bpj dan 172,9 bpj.

\section{Saran}

Sebaiknya dilakukan penelitian untuk mengisolasi senyawa aktif antioksidan dari kayu Bayur Sulawesi (Pterospermum celebicum Miq.) dan uji bioaktivitas.

\section{UCAPAN TERIMA KASIH}

Terima kasih diucapkan kepada Koordinator Program Hibah Kopetensi IMHERE Fakultas Farmasi Universitas Hasanuddin yang telah membiayai penelitian ini.

\section{DAFTAR PUSTAKA}

1. Masrifah YR. 2006. Isolasi dan Uji Aktivitas Anti Radikal Bebas Senyawa Fenolik Fraksi Etil Asetat dari Kulit Batang Cassia spectabilis DC. Skripsi. Fakultas MIPA Universitas Airlangga. Surabaya. hal. 1-2, 31

2. Meng TC, Yu-Tang T, Shang TC. Antioxidant activities of ethanolic extracts from the twigs of Cinnamomum osmophloeum. JBT [serial on the Internet]. 2007 May 2; [2009 June 1]; 99. Available from: http://www. ezplib.ukm.com/

3. Rohman A, Riyanto S. Daya Antioksidan Ekstrak Etanol Daun Kemuning (Murraya paniculata (L) Jack) secara in vitro. MFI. 2005. Vol. 16 no. 3. hal. 136-140.

4. Amrun MH, Umiyah. Pengujian Antiradikal Bebas Difenilpikril Hidrazil (DPPH) Ekstrak Buah Kenitu ( Chrysophyllum cainito L.) Dari Daerah Sekitar Jember. JID. 2005. Vol. 6 no. 2. hal. 110-114.

5. Prawira RSA. 1987. Daftar Nama PohonPohonan Sulawesi Selatan, Tenggara dan Sekitarnya. Badan Litbang Kehutanan Sul-Sel. Makassar. hal. 99.

6. Sosef MSM, Hong LT, Prawirohatmodjo S. 1998. Plant Resources of South-East Asia. PROSEA. Bogor. hal. 479-482.

7. Marzuki A, Alfian N, Nunuk HN, Harlim T. Pemeriksaan Farmakognostik Tumbuhan Pterospermum celebicum Miq. dan Penapisan Komponen Kimia Secara Kromatografi Lapis Tipis. Di dalam: Litaay M, Fachrudin, Soekendarsi E, Zulkifli A, editor. Prosiding Seminar Nasional Biologi XIX. Makassar; 9-10 Juli 2008. hal. 403-407.

8. Harborne JB. 1987. Metode Fitokimia. Terjemahan oleh Padmawinata K \& Soediro I. Bandung. Penerbit ITB. hal. 120.

9. Hanani E, Mun'in A, Sekarini R. Identifikasi Senyawa Antioksidan Dalam Spons Callyspongia sp. Dari Kepulauan Seribu. MIK. 2005. Vol. II no. 3. hal. 127-133.

10. Burhanudin. 2009. Tumbuh-tumbuhan Khas Sulawesi. $\quad$ www.lorelindu.wordpress.com. diakses tanggal 24 Juli 2009.

11. Irawati et.al. 2008. List of Plants Species Cultivated in the Bogor Botanical Gardens. Pusat Konservasi Tumbuhan Kebun Raya Bogor, LIPI.

12. Boer E, Lemmens RHMJ. 2009. Informasi Spesien Tumbuhan Keras. www.plantamol.com/informasi-spesiespterospermum/html. diakses tanggal 24 Juli 2009. 
Uji aktivitas antioksidan ekstrak kayu bayur sulawesi (Pterospermum celebicum miq.) Dengan metode penangkapan radikal bebas dpph (2,2-diphenyl-1-picryl-hydrazyl)

13. Winarsi H. 2007. Antioksidan Alami dan Radikal Bebas Potensi dan Aplikasinya dalam Kesehatan. Penerbit Kanisius. Yogyakarta. hal. $77-82$.

14. Suratmo. Potensi Ekstrak Daun Sirih Merah (Piper crocatum) Sebagai Antioksidan. MFI. 2007. Vol. 15 no. 1. hal.115-119.

15. Direktorat Jendral Pengawasan Obat dan Makanan. 1979. Farmakope Indonesia. Ed.3. Departemen Kesehatan Republik Indonesia. Jakarta. hal. 9

16. Gritter RJ, Bobbit JM, Schwarting AF. 1991. Pengantar Kromatografi. Ed.2. ITB. Bandung. hal. 9-12

17. Direktorat Jendral Pengawasan Obat dan Makanan. 1979. Sediaan Galenik. Ed.2. Departemen Kesehatan Republik Indonesia. Jakarta. hal. 16

18. Markham KR. 1988. Cara Mengidentifikasi Flavonoid. Penerbit ITB. Bandung. hal. 15-16.

19. Vermerris W, Nicholson R. 2008. Phenolic Compound Biochemistry. Spinger Science. West Lafayette USA. pp. 151-152.
20. Sastrohamidjojo H. 1985. Spekroskopi. Penerbit Liberty. Yogyakarta. hal. 11-15.

21. Solomons TWG. 1980. Organic Chemistry. $2^{\text {nd }}$ edition. John Willey and Sons. University of South Florida. New York. p. 413.

22. Wahjuni T. 2006. Dua Santon Terprenilasi dan Uji Antioksidan pada Ekstrak n-Heksan dari Kulit Batang Garcinia tetranda Pierre. Tesis Program Pascasarjana ITS. Surabaya. hal. 35.

23. Sulistyarini PD. 2009. Uji Aktivitas Antiradikal Bebas dari Ekstrak Inti Biji Bagore (Caesalpinia crista Linn.). Skripsi Fakultas Farmasi Universitas Hasanuddin. Makassar. hal. 37-38.

24. Tahir I, Wijaya K, Widianingsih D. Terapan Analisis HANSCH untuk Aktivitas Antioksidan Senyawa Turunan Flavon/Flavonol. Makalah disajikan dalam Seminar Khemometri. Jurusan Kimia FMIPA Universitas Gajah Mada. Yogyakarta 25 Januari 2003. 